\title{
A bidirectional resonant converter based on wide input range and high efficiency for photovoltaic application
}

\author{
Ibrahim Alhamrouni', M. R. Bin Hamzah², Mohamed Salem ${ }^{3}$, Awang Jusoh ${ }^{4}$, Azhar Bin Khairuddin ${ }^{5}$, \\ T. Sutikno ${ }^{6}$ \\ 1,2 Electrical Engineering Section, University Kuala Lumpur (UniKL BMI), Gombak 53100, Malaysia \\ ${ }^{3}$ School of Electrical and Electronic Engineering, Universiti Sains Malaysia, 14300 Nibong Tebal, Pulau Pinang, Malaysia \\ ${ }^{4,5}$ School of Electrical Engineering, Universiti Teknologi Malaysia, 81300 Skudai, Malaysia \\ ${ }^{6}$ Department of Electrical Engineering, Universitas Ahmad Dahlan, Yogyakarta, Indonesia
}

\begin{tabular}{l} 
Article Info \\
\hline Article history: \\
Received Dec 17, 2018 \\
Revised Feb 27, 2019 \\
Accepted Apr 20, 2019 \\
\hline
\end{tabular}

Keywords:

Bidirectional Converter

Photovoltic (PV)

Power Condititiong System

(PCS)

Resonant Converter

\begin{abstract}
This work highlights a modular power conditioning system (PCS) in photovoltaic (PV) applications which consists with a DC-DC converter. The converter is able to regulate and amplify the input DC voltage produced by the PV panal. The implementation of Mosfet as bidirectional switch on the converter yields greater conversion ratio and better voltage regulation than a conventional DC-DC step up converter and PWM resonant converter. It also reduces the switching losses on the output DC voltage of the converter, as the MOSFET switches on primary winding of converter switch on under ZVS conditions. The proposed resonant converter has been designed, with the modification of series resonant converter and PWM boost converter that utilizes the high frequency of AC bidirectional switch to eliminate the weaknesses of used converters. The topology of the proposed converter includes the mode of operations, designing procedure and components selection of the new converter elements. This topology provides a DC output voltage to the inverter at range of about $120 \mathrm{Vac}-208 \mathrm{Vac}$.
\end{abstract}

Copyright (C) 2019 Institute of Advanced Engineering and Science. All rights reserved.

\section{Corresponding Author:}

Ibrahim Alhamrouni, Electrical Engineering Section, University Kuala Lumpur British Malaysian Institute (UniKL BMI), Gombak 53100, Malaysia.

Email: ibrahim.mohamed@unikl.edu.my

\section{INTRODUCTION}

Photovoltaic (PV) energy is one of the renewable energies available in daily life as an option or backup to the other electrical energy supply. Besides, PV energy generation causes no pollution to environment as it is green technology. In addition, the PV energy usage and demand have achieved significant growth in recent years due to constant researches and developments and the civilians' awareness towards clean environment. PV energy is gained by harnessing the solar energy of sunlight's photon using PV modules or solar panel $[1,2]$. Each PV module has different direct current (DC) output, thus given the wide input current range to the Power Conditioning System (PCS). In PV system, PCS acts as an inverter that converts the DC output from PV module to alternate current (AC). The PCS is connected to the electric power grid and equipped with Maximum Power Point Tracker (MPP Tracker). The purpose of this tracker is to improve the efficiency of solar power generation. This tracker has Maximum Power Point Tracking (MPPT) algorithm to maximize the power extraction from PV modules under certain factors and conditions $[3,4]$. There are 3 types of PV PCS configuration; modular, string and centralized. Among these configurations, the PV PCS modular type has been considered as the best and commonly used in PV installation because its efficiency in harvesting the energy. What makes PV PCS modular type is the best are the implementation of Module Integrated Converter (MIC) on each PV module for MPPT and it varies in 
connection of output AC to the grid (called as micro-inverter) or output $\mathrm{AC}$ to output $\mathrm{DC}$ (called as microconverter)[5]. In order to obtain the best from solar energy due to many factors affecting the sunlight, the modular PV PCS has to work with high efficiency over wide input range. There are several electronic approaches used to make PV PCS modular type working in high efficiency condition, as example, flyback converter variants, LLC converter, isolated Pulse Width Modulation (PWM) converter and series resonant converter, to meet the requirement of DC-DC micro-converter[6]. These kinds of approaches are the isolated DC-DC converter type, however they have several weaknesses and suffer some inability to meet desired outcome. Besides, the high efficiency has to be achieved by meeting the wide input voltage requirement, zero voltage switching (ZVS) on low circulated currents and zero current switching (ZCS). ZVS and ZCS are the process of switching turn-on and turn-off of converter's switch during zero voltage and zero current input. The importance of the converter achieving ZVS and ZCS are to reduce losses during switching operation and provide soft switching method to reduce the electromagnetic interference [7-9].

Based on the previous studis of DC-DC isolated resonant converter topologies, it can be described that all the converters suffer the drawbacks in order to achieve the desired output. Hence, in order to obtain high efficiency over wide input range, soft switching in Zero Current Switching (ZCS) and Zero Voltage Switching (ZVS) condition, maximum direct power transfer from source to load and good voltage regulation through fixed PWM control, the development of new isolated resonant converter is considered[8]. In developing the new isolated resonant converter, several processes has been planned properly in order to avoid the drawbacks and maintaining the soft switching and good voltage regulation along the operation. The processes consist of the selection of transformer turns ratio, the designation of resonant tank, transformer design and dead time selection and the most important thing, the selection of semiconductor devices[7]. Besides, the study of previous works on isolated DC-DC resonant converters was really much help in order to develop the new isolated resonant converter. This is because the research can benefits the strengths and relates the certain important points of the previous studies in terms of the circuit designation and modes of operations. Thus, the new developed resonant converter operates much like conventional series resonant converter and PWM boost converter [3]. The newly proposed design has several modifications to the conventional series resonant converter, LLC converter and PWM boost converter, in order to obtain the high efficiency over wide input range under fixed-frequency control [10-12]. One of the significant changes on the proposed circuit is adding bidirectional AC switch on secondary winding of circuit. The bidirectional AC switch is MOSFET (Metal Oxide Semiconductor Field Effect Transistor). The purpose of adding bidirectional $\mathrm{AC}$ switch on secondary winding is to utilizing its high frequency for regulation capability of the output, either the output has load or no load by using PWM boost converter design and operation concept $[4,13,14]$. Besides, it helps to maximize the direct power transfer from source to load and providing good wide range of regulation in its operation, thus increasing the converter's efficiency [15-18]. The paper suggests the proposed converter shall provide the high DC-DC voltage conversion ratio, regulates the output transformer voltage and reduce the switching losses when MOSFET switches on primary winding of converter's transformer achieve ZVS. The new proposed resonant converter has been designed, with the modification of series resonant converter and PWM boost converter that utilizizes the high frequency of AC bidirectional switch to overcome all weaknesses of previous types of converters. The topology of proposed converter includes the mode of operations, designing procedure and components selection of the new proposed resonant converter.

\section{CIRCUIT CONFIGRATON AND OPERATION MODES}

The proposed isolated resonant converter has 8 modes of operations. The converter consists of 4 MOSFETs N-Channel on the primary winding of transformer to mitigate the switch count as they form a full bridge switch network, S1, S2, S3 and S4. The additional of two drain-connected of MOSFETs at the secondary winding of transformer as bidirectional switch, S5 allows the converter to operate in conventional series resonant converter mode during OFF condition and PWM boost converter mode during ON condition. The inductor Lr at the secondary winding transformer either can be a resonant inductor or a leakage inductance. The $\mathrm{n}$ and $\mathrm{Lm}$ from the circuit represent the turns ratio and magnetizing inductance. The resonant inductor, $\mathrm{Lr}$ along with output resonant capacitors, $\mathrm{Cr} 1$ and $\mathrm{Cr} 2$ determining the series resonant frequency, $\mathrm{fr}$ for the switch network operation. The Lm value is larger than $\mathrm{Lr}$, while the output capacitor, Co value is larger than $\mathrm{Cr} 1$ and $\mathrm{Cr} 2$ combined, which also one of the factor that allows the converter to operate in series resonant mode during S5 is OFF. The utilization of PCS in PV application steps up the low voltage into high voltage. Besides, the isolated DC - DC converter type provides the isolation between source and loads which is necessary. Other than that, it also tracks the maximum power point of PV module effectively.

Int J Pow Elec \& Dri Syst, Vol. 10, No. 3, Sep 2019 : 1469 - 1475 


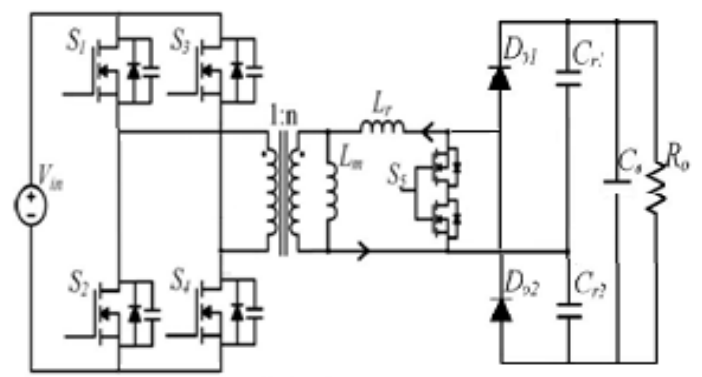

Figure 1. The circuit configtation of the proposed converter

\subsection{Mode 1 and mode 5}

The circuit operates in PWM boost mode. The positive voltage is generated when switch S1 and S4 are $\mathrm{ON}$ during Mode 1. On the other hand, the switch S2 and S3 generates the negative voltage during Mode 5 when both are ON. Bidirectional switch, S5 is ON. The secondary winding of transformer is shorted due to nearly zero current and voltage across leakage inductance, Lr and capacitor Cr1. During the Mode 5, the S2 and $\mathrm{S} 3$ are $\mathrm{ON}$ and generate the negative voltage.

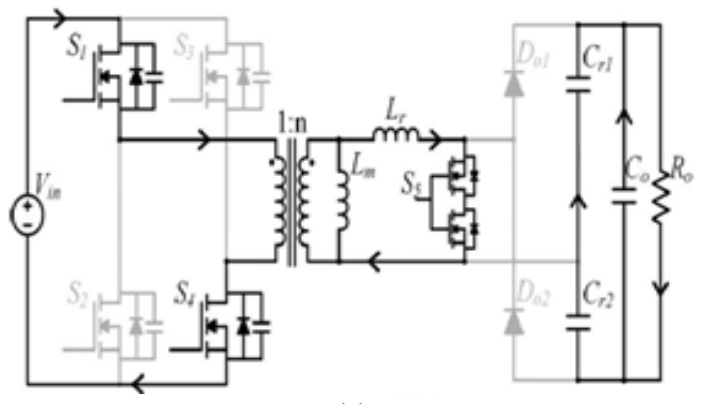

(a)

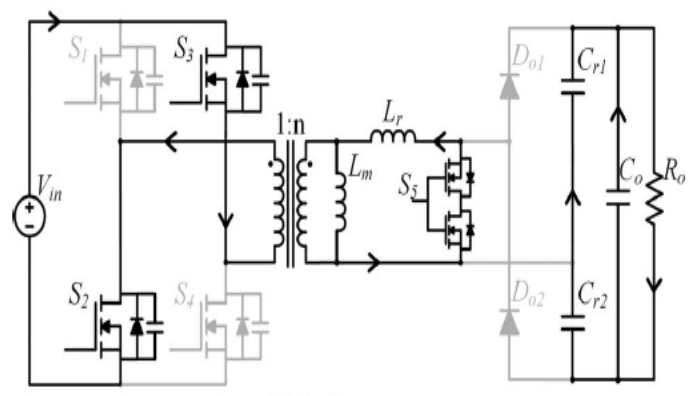

(b)

Figure 2. Operation modes; (a) mode 1, and (b) mode 5

\subsection{Mode 2 and mode 6}

The circuit operates as conventional series resonant converter as the bidirectional switch, S5 is OFF. The resonant inductor, Lr has been charged completely during previous stages (Mode 1 and Mode 5) and discharged after entering these stages through the capacitor duo, Cr1 and Cr2. When the switch S1 and S4 are ON during Mode 2, the converter operates in positive duty cycle, while vice versa when S2 and S3 are ON during Mode 6.

\subsection{Mode 3 and mode 7}

The converter operates in idle mode. During these stages, the current of inductor Lr declines to zero. Besides, there is no direct power transfer between source and loads as the converter works with fixed frequency. Also, the zero voltage switching (ZVS) is achieved on the primary winding and zero current switching (ZCS) is achieved on the secondary winding. The utilized small current allows the converter to operate close to series resonant frequency.

\subsection{Mode 4 and mode 8}

These stages are the dead time period of the converter. The magnetizing inductor, Lm has the maximum current value to supplies the converter during Mode 4. The S2 and S3 are turn on under ZVS condition. During Mode 8, the S2 and S3 are initially off. The current in Lm reaches its minimum value, charges the parasitic capacitance of S2 and S3 and discharging those of S1 and S4. 


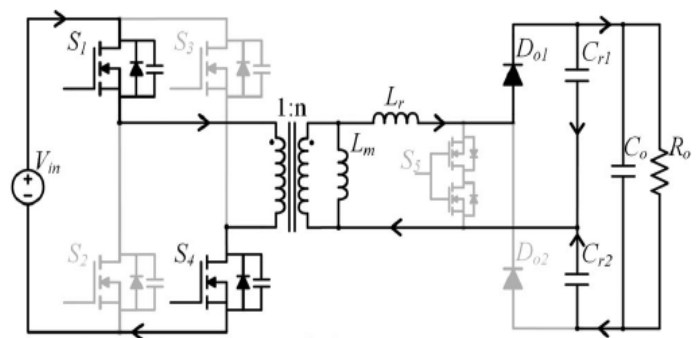

(a)

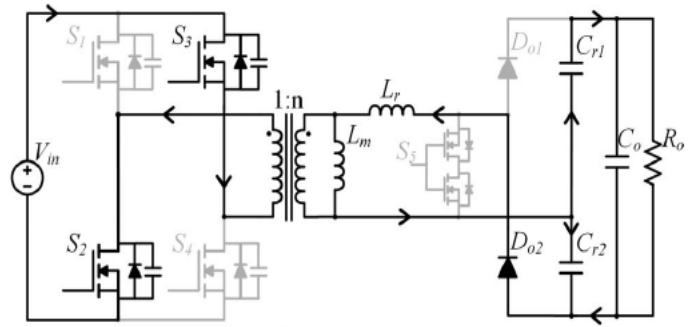

(b)

Figure 3. Operation modes; (a) mode 2, and (b) mode 6

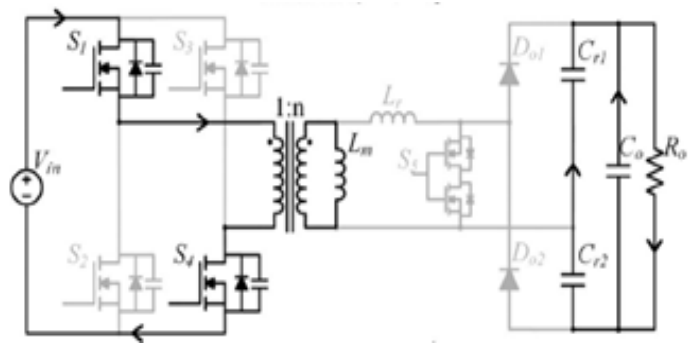

(a)

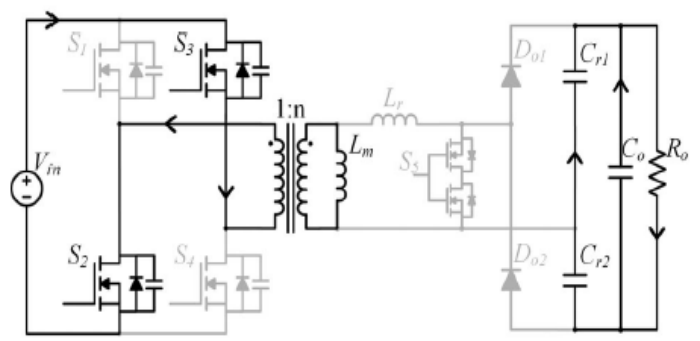

(b)

Figure 4. Operation modes; (a) mode 3, and (b) mode 7

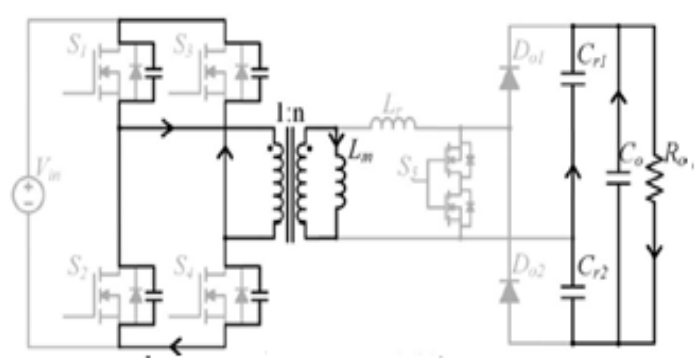

(a)

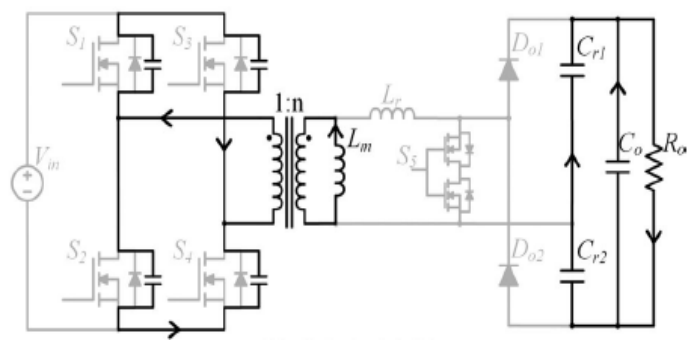

(b)

Figure 5. Operation modes; (a) mode 4, and (b) mode 8

\section{PROPOSED CONVERTER PARAMETRES DESIGN}

The converter also designed to produce output power of $350 \mathrm{~W}$. As the inverter is about to produce maximum output AC voltage of $230 \mathrm{~V}$, the converter also expected to produce DC voltage of $325 \mathrm{~V}$. The switching time, Ts is set at $60 \mu \mathrm{s}$ and switching frequency is set at $17 \mathrm{kHz}$ which based on LLC resonant converter topology in [13]. In designing the resonant tank, first thing first is choosing the large value of resonant inductor, Lr. The internal reactance of resonant inductor, XLr and resonant capacitor, XCr is set at $12.94 \Omega$ which also based on LLC resonant converter topology. The large Lr value is necessary for Mode 1 and Mode 2 to last longer than Mode 3. This is because there's no power transfer from load to source in Mode 3 besides by minimizing this operation mode period, it will increase the efficiency of power conversion. The value of Lr can be determined as ;

$$
\operatorname{Lr}=\frac{\mathrm{XLr}}{2 \pi \mathrm{Fr}}
$$

Meanwhile, the resonant capacitors, $\mathrm{Cr} 1$ and $\mathrm{Cr} 2$ are chosen based on the resonant frequency needed. However, the ripple voltage across those capacitors cannot exceed their own DC voltage. The DC voltage value of the capacitors is half of the output voltage value. The voltage stress across S5 and the resonant capacitors can be reduced by selecting the lower $\mathrm{Cr}$ value. The $\mathrm{Cr}$ value can be determined as ;

Int J Pow Elec \& Dri Syst, Vol. 10, No. 3, Sep 2019 : 1469 - 1475 


$$
\mathrm{Cr}=\frac{\mathrm{PoTs}}{\mathrm{Vo}^{2}}
$$

On the other hand, the resonant frequency, $\mathrm{Fr}$ of the converter based on $\mathrm{Cr}$ is determined as ;

$$
\mathrm{Fr}=\frac{1}{2 \pi \mathrm{XCrCr}}
$$

It is more important to choose suitable value of magnetizing inductance, $\mathrm{Lm}$ to obtain the desired outcome. Still, choosing the larger value of Lm over Lr is necessary to compensate the circulating current on primary winding, thus maximizing the power transfer from source to load besides increasing the efficiency of power conversion. The Lm is 20 times bigger than value of Lr. Last but not least, if the input voltage of the converter is greater than the nominal voltage, the S5 duty cycle becomes zero and the PWM from the primary side switching will provides the conversion ratio that less than the series resonant converter. If the input voltage of the converter is less than the nominal voltage, the utilization of bidirectional switch will provide the conversion ratio that greater than series resonant converter. The number of turns, $\mathrm{n}$ can be expressed as ;

$$
\mathrm{n}=\frac{\mathrm{Vo}}{2 \mathrm{Vin}}
$$

\section{RESULTS AND DISCUSSION}

The simulation of the converter is done by MATLAB 2016b version. The converter was designed as suggested in previous csection. By using the mathematical formula shown in previous section, the converter was designed to fulfill the requirement to produce DC output voltage to be inverted by the inverter for AC output voltage range $120 \mathrm{Vac}-230 \mathrm{Vac}$. With the implementation of MOSFETs as bidirectional switch on secondary winding, this hybrid converter yields greater conversion ratio than conventional step up DC-DC converter and PWM boost converter with smaller transformer turns ratio and smaller resonant tank parameters. The converter was designed to have the input voltage at range $15 \mathrm{~V}$ to $50 \mathrm{~V}$. However, the converter must have nominal input voltage of $30 \mathrm{~V}$ and less to be operated under the normal AC switch operation in order to be produced by inverter for AC output voltage of $120 \mathrm{Vac}-230 \mathrm{Vac}$. Thus the chosen nominal input voltage is $30 \mathrm{~V}$. Figure 6 shows the measured gate voltage and collector voltage of all switches $(\mathrm{S} 1-\mathrm{S} 4)$ at full load condition. The collector voltage VDS dropped to zero, before the switches were turned on. Thus, all the switches were turned on at ZVS.
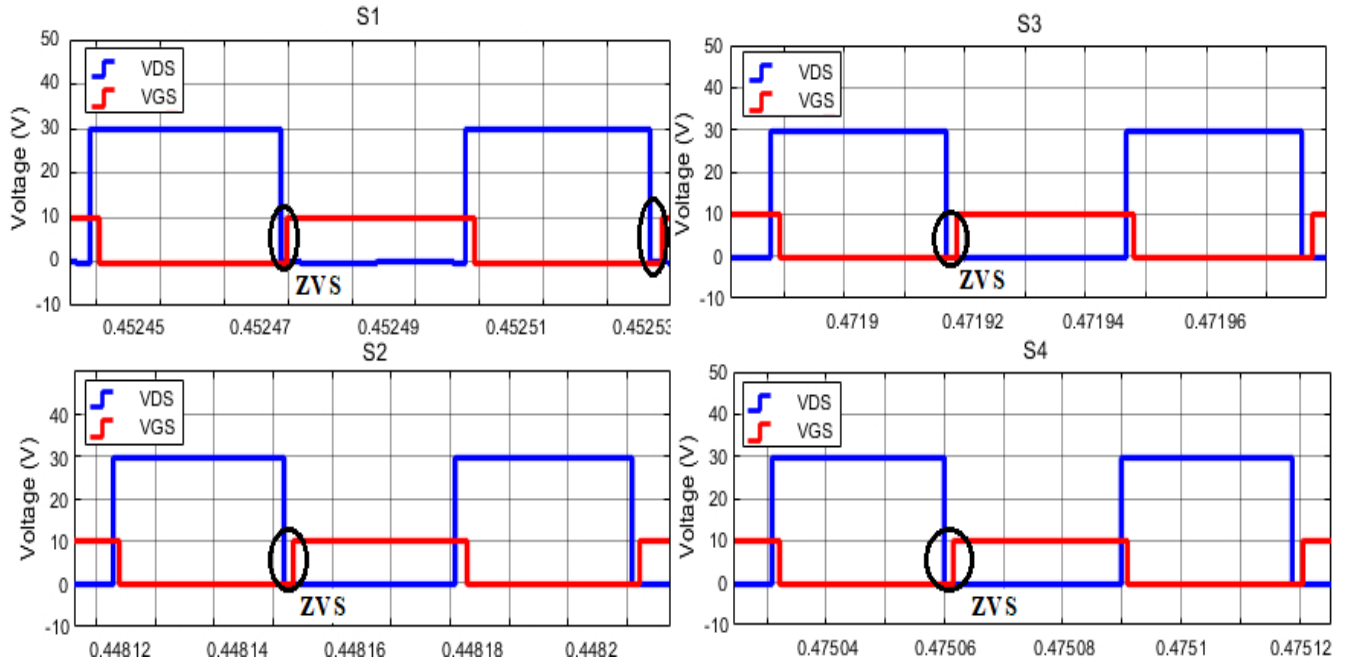

Figure 6. Measured waveforms of the gate voltage and drain voltage for each switch separately

As the 4 power MOSFETs sorted as full-bridge switch on primary winding of the converter, the transformer output voltage produce voltage peak to peak AC $340.6 \mathrm{~V}$ from the $30 \mathrm{~V}$ input voltage. The transformer output voltage peaked at maximum value $171.8 \mathrm{~V}$ and minimum value $-168.9 \mathrm{~V}$ as shown in Figure 8 .

A bidirectional resonant converter based on wide input range and ... (Ibrahim Alhamrouni) 


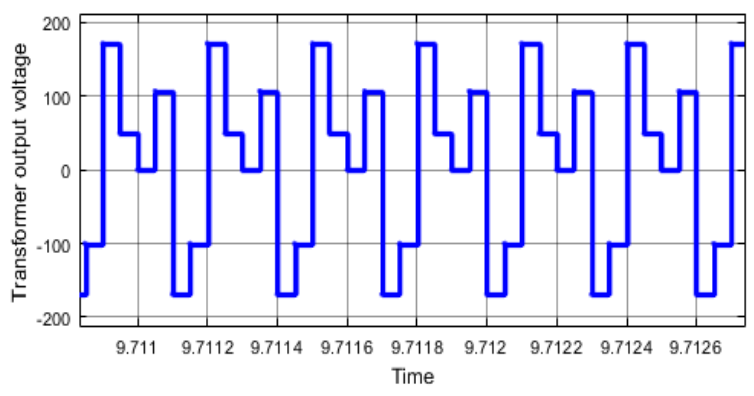

Figure 7. Transformer output voltage Vto

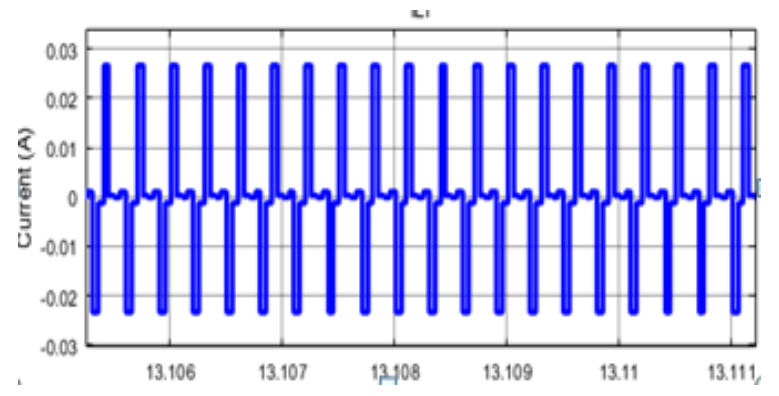

Figure 8. Measured waveform of resonant inductor current $i \mathrm{Lr}$

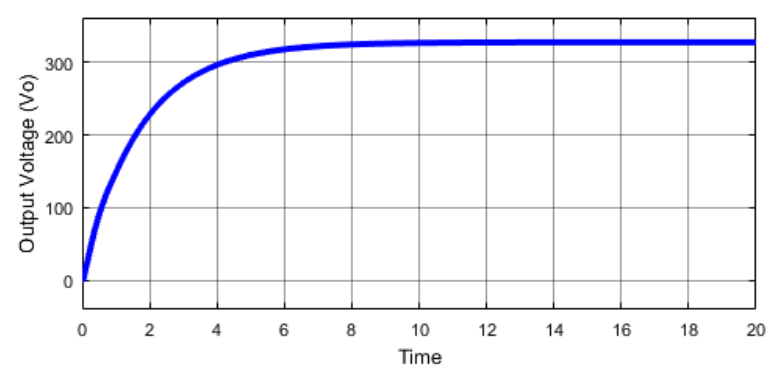

Figure 9. Output voltage Vo

With another installment of MOSFETs on secondary winding of converter as bidirectional switch, the transformer output voltage is regulated and boosted. Thus, produce the DC voltage output of $327.7 \mathrm{~V}$ as shown in Figure 9. The switching losses were caused by the element called parasitic capacitance. This element is unavoidable when the transistors, diodes and other components that have internal capacitance are draw close to each other in the circuit. The proposed converter also has switching losses but it was too small to be compared with step up DC-DC converter. This is because HRC has the attachment of MOSFETs on secondary winding to reduce the switching losses. In this contest, the proposed converter is more reliable than step up DC-DC converter.

\section{CONCLUSION}

The proposed resonant converter, HRC has proven that it can yield higher conversion ratio of the voltage than any other resonant converter, besides regulating the transformer output voltage to provide a sufficient voltage supply for the inverter in the PV system. In addition, the designed DC-DC converter is able to track the MPP of PV panels while operating under the different input voltages. Thus, HRC has fulfilled the criteria and goals. The implementation of two MOSFETs as bidirectional switch on the secondary winding of converter's transformer has also helped reducing switching losses that occur after the full bridge MOSFETs on the primary winding achieves ZVS. Although HRC has 8 different modes of operation, the suitable 
injection of switching frequency on the MOSFETs made the converter switching the mode after mode very fast and smooth. After all, HRC is the best resonant DC-DC converter to be implemented on modular PCS of PV. In the future, HRC and the inverter can be combined together as one part in modular PCS. It will be a DC-AC converter, thus reducing the components and cost to be used. Further research and development of the recommended project will be considered. With one condition, the converter must produce sufficient output voltage to utility grid with good voltage regulation.

\section{ACKNOWLEDGEMENTS}

The authors would like to express their gratitude to Universiti Kuala Lumpur for supporting and funding this research under grant No. str18005.

\section{REFERENCES}

[1] A. Ciocia, V. A. Boicea, G. Chicco, P. Di Leo, A. Mazza, E. Pons, et al., "Voltage Control in Low-Voltage Grids Using Distributed Photovoltaic Converters and Centralized Devices," IEEE Transactions on Industry Applications, vol. 55, pp. 225-237, 2019

[2] I. Alhamrouni, M. Rahmat, F. Ismail, M. Salem, A. Jusoh, and T. Sutikno, "Design and development of SEPIC DCDC boost converter for photovoltaic application," International Journal of Power Electronics and Drive Systems (IJPEDS), vol. 10, pp. 406-413, 2019.

[3] M. A. G. De Brito, L. Galotto, L. P. Sampaio, G. d. A. e Melo, and C. A. Canesin, "Evaluation of the main MPPT techniques for photovoltaic applications," IEEE transactions on industrial electronics, vol. 60, pp. 1156-1167, 2013.

[4] T. Esram and P. L. Chapman, "Comparison of photovoltaic array maximum power point tracking techniques," IEEE Transactions on energy conversion, vol. 22, pp. 439-449, 2007.

[5] T. LaBella, W. Yu, J.-S. J. Lai, M. Senesky, and D. Anderson, "A bidirectional-switch-based wide-input range high-efficiency isolated resonant converter for photovoltaic applications," IEEE transactions on power electronics, vol. 29, pp. 3473-3484, 2014.

[6] M. Salem, A. Jusoh, N. R. N. Idris, T. Sutikno, and Y. M. Y. Buswig, "Phase-shifted Series Resonant Converter with Zero Voltage Switching Turn-on and Variable Frequency Control," International Journal of Power Electronics and Drive Systems (IJPEDS), vol. 8, pp. 1184-1192, 2017.

[7] R. Beiranvand, B. Rashidian, M. R. Zolghadri, and S. M. H. Alavi, "A design procedure for optimizing the LLC resonant converter as a wide output range voltage source," IEEE Transactions on Power Electronics, vol. 27, pp. 3749-3763, 2012.

[8] R. Beiranvand, B. Rashidian, M. R. Zolghadri, and S. M. H. Alavi, "Using LLC resonant converter for designing wide-range voltage source," IEEE Transactions on Industrial Electronics, vol. 58, pp. 1746-1756, 2011.

[9] M. Salem, A. Jusoh, N. N. Idris, T. Sutikno, and I. Abid, "ZVS Full Bridge Series Resonant Boost Converter with Series-Connected Transformer," International Journal of Power Electronics and Drive Systems, vol. 8, pp. 812825, 2017.

[10] H. Hu, X. Fang, F. Chen, Z. J. Shen, and I. Batarseh, "A modified high-efficiency LLC converter with two transformers for wide input-voltage range applications," IEEE Transactions on Power Electronics, vol. 28, pp. 1946-1960, 2013.

[11] B.-G. Chung, K.-H. Yoon, S. Phum, E.-S. Kim, and J.-S. Won, "A novel LLC resonant converter for wide input voltage and load range," in 8th International Conference on Power Electronics-ECCE Asia, pp. 2825-2830. 2011.

[12] H. Choi and P. C. Team, "Design considerations for an LLC resonant converter," in Fairchild Power Seminar, pp. 82-3. 2007.

[13] W. Yu, B. York, and J.-S. Lai, "Inductorless forward-flyback soft-switching converter with dual constant on-time modulation for photovoltaic applications," in 2012 IEEE Energy Conversion Congress and Exposition (ECCE), 2012, pp. 3549-3555. 2012.

[14] Z. Liang, R. Guo, J. Li, and A. Q. Huang, "A high-efficiency PV module-integrated DC/DC converter for PV energy harvest in FREEDM systems," IEEE Transactions on Power Electronics, vol. 26, pp. 897-909, 2011.

[15] I. Alhamrouni, W. I. Hanis, M. Salem, F. M. Albatsh, and B. Ismail, "Application of DC-DC converter for EV battery charger using PWM technique and hybrid resonant," in 2016 IEEE International Conference on Power and Energy (PECon), pp. 133-138. 2016.

[16] M. Salem, A. Jusoh, N. R. N. Idris, H. S. Das, and I. Alhamrouni, "Resonant power converters with respect to passive storage (LC) elements and control techniques-An overview," Renewable and Sustainable Energy Reviews, vol. 91, pp. 504-520, 2018.

[17] I. Alhamroun, M. Salem, A. Jusoh, N. R. N. Idris, B. Ismail, and F. M. Albatsh, "Comparison of two and four switches inverter feeding series resonant converter," in 2017 IEEE Conference on Energy Conversion (CENCON), pp. 334-338. 2017.

[18] M. Salem, A. Jusoh, N. R. N. Idris, and I. Alhamrouni, "Comparison of LCL resonant converter with fixed frequency, and variable frequency controllers," in 2017 IEEE Conference on Energy Conversion (CENCON), pp. 84-89. 2017. 